Diabetologia 11, 83-88 (1975)

(c) by Springer-Verlag 1975

\title{
Diurnal Variation in the Effects of Insulin on Blood Glucose, Plasma Non-Esterified Fatty Acids and Growth Hormone
}

\author{
T. Gibson, L. Stimmler, R. J. Jarrett, P. Rutland and M. Shiu \\ Guy's Hospital, London, England \\ Received: June 24, 1974, and in revised form: October 31, 1974
}

\begin{abstract}
Summary. Insulin $0.05 \mu / \mathrm{kg}$ body weight was injected intravenously into 14 subjects both at $8 \mathrm{a} . \mathrm{m}$. and $5 \mathrm{p} . \mathrm{m}$. in random order $12 \mathrm{hrs}$ after a $50 \mathrm{~g}$ glucose meal. Fasting glucose levels were similar in both cases but the $48 \% \pm 10 \%$ fall in blood glucose in the morning was significantly greater $(p<0.001)$ than that of $34 \% \pm 7 \%$ in the afternoon. Fasting plasma NEFA, however, varied markedly between $477 \pm 150$ $\mu$ EqlL in the morning and $725 \pm 195 \mu \mathrm{EqlL}$ in the afternoon $(p<0.001)$ and the fall after insulin injection $(64 \% \pm 14 \%)$ was greater in the afternoon than in the morning $(47 \% \pm$ $15 \%)(p<0.001)$. There was an inverse relationship between proportional glucose disappearance and proportional NEFA disappearance $(p<0.01)$. The calculated caloric change in
\end{abstract}

the plasma, the sum of the falls in glucose and NEFA, were very similar in both morning $(2.2 \pm 0.5 \mathrm{Cals} / \mathrm{l})$ and afternoon $(2.3 \pm 0.5 \mathrm{Cals} / 1)$, i.e., in spite of the variations of glucose and NEFA metabolism produced by insulin at different times, the nett effect, in terms of energy, was the same. Plasma growth hormone response in the afternoon was found to be enhanced compared with the morning values, although the degree of hypoglycaemia was greater in the morning.

Key words: Insulin, glucose, non-esterified fatty acids, growth hormone, diurnal variations.
The blood sugar response to oral [7] or intravenous [19] glucose is significantly impaired in the afternoon compared with the morning. There is a poorer initial insulin response in afternoon tests $[8,20,1,19]$ which may, in part, account for this difference. However, in a study of 30 subjects who were given exogenous insulin both in the morning and afternoon, Gibson and Jarrett [3] showed that the hypoglycaemic action of exogenous insulin was less in the afternoon than the morning; this 'insulin resistance' may also be implicated in the diurnal variation of glucose tolerance.

Glucose levels fall more slowly in diabetics than in non-diabetic subjects following intravenous insulin administration [17]. In that study it was suggested that the impaired rate of fall of glucose was due to slower insulin disappearance from the blood, itself possibly secondary to slower insulin metabolism. The purpose of the present study was to see whether a similar relationship between glucose and insulin disappearance might account for the differences in insulin sensitivity between morning and afternoon. The effect of insulin on levels of nonesterified fatty acids (NEFA) was also investigated, as were the effects on plasma growth hormone levels.

\section{Materials and Methods}

Fourteen male volunteers, aged between 26 and 68 years, with no clinical evidence or history of diabetes mellitus or other disorders of carbohydrate metabolism, were studied. A meal of $50 \mathrm{~g}$ of glucose was given at 12 midnight, or at 9 a.m., followed by an eight hour fast until the test. The tests were performed in random order, 4 days apart.

An indwelling needle was placed in an antecubital vein of one arm and an initial blood sample was obtained. Porcine insulin ('Actrarapid', Novo), 0.05 units $/ \mathrm{kg}$ body weight, was then injected intravenously into the other arm and further samples collected at accurately timed and frequent intervals up to $80 \mathrm{~min}$ after the injection. Each sample was assayed for plasma insulin, NEFA and growth hormone, and blood sugar.

Blood sugar was estimated by the ferricyanide reduction method on an Auto Analyser (Technicon method N. 9a.). Plasma NEFA were measured by the method of Carruthers and Young [2]. Double antibody immunochemical techniques were used to measure insulin [13] and growth hormone [6].

\section{Results}

\section{A. Glucose Levels}

The fasting levels of glucose in the morning (77.1 \pm $18.5 \mathrm{mg} / 100 \mathrm{ml})$ were similar to those in the afternoon $(79.3 \pm 13.5 \mathrm{mg} / 100 \mathrm{ml})(p>0.1)$. 
The mean glucose levels from $5 \mathrm{~min}$ to $60 \mathrm{~min}$ are illustrated in Fig. 1. In both series of tests glucose levels fell progressively to a nadir (which occurred on average at $29 \pm 6 \mathrm{~min}$ in the morning and $32 \pm 8$ min in the afternoon $-p>0.1$ ). In the morning the lowest value was $40.2 \pm 9.5 \mathrm{mg} / 100 \mathrm{ml}$ and in the afternoon the minimum glucose level was $54.0 \pm 13.2$ $\mathrm{mg} / 100 \mathrm{ml}(p<0.0005)$. The total fall in blood glucose from $5 \mathrm{~min}$ to the nadir was significantly correlated with the fasting glucose level $(r=0.76$; $p<0.01$ ). There was a $47.6 \pm 10.2$ per cent fall in glucose levels from $5 \mathrm{~min}$ to the nadir in the morning, compared with $33.9 \pm 7.0$ per cent in the afternoon $(p<0.0005)$.

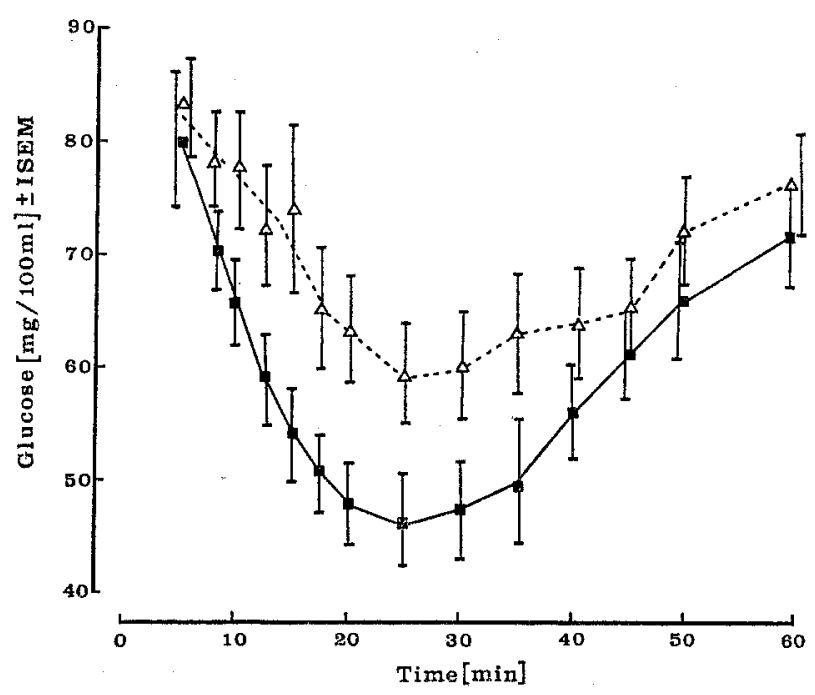

Fig. 1. Mean glucose levels in both morning and afternoon following insulin injection

A semi-logarithmic plot of mean glucose levels against time was linear between 5 and $20 \mathrm{~min}$ after insulin injection. The rate constant for the glucose fall over this period was $3.4 \pm 1.5 \mathrm{per}$ cent $/ \mathrm{min}$ in the morning and $2.0 \pm 0.9$ per cent $/ \mathrm{min}$ in the afternoon $(p<0.0025)$.

\section{B. Insulin Levels}

Mean fasting insulin levels in the morning $(18 \pm 6$ $\mu \mathrm{U} / \mathrm{ml}$ ) did not differ significantly from fasting levels in the afternoon $(20 \pm 7 \mu \mathrm{U} / \mathrm{ml})$. Neither in the arithmetic or in the semi-logarithmic plot (not shown) is there any difference in the two slopes. In both morning and afternoon, insulin levels fell progressively to an equilibrium value which was almost identical with the mean, fasting insulin value $(19 \mu \mathrm{U} / \mathrm{ml})$. Glucose levels continued to fall until insulin had almost ap- proached the initial fasting value. There was a highly significant correlation $(\mathrm{r}=0.70 ; p<0.001)$ between the time of the glucose nadir and the time at which insulin levels had dropped to $10 \mu \mathrm{U} / \mathrm{ml}$ above the fasting value Fig. 2.* The mean time taken for in-

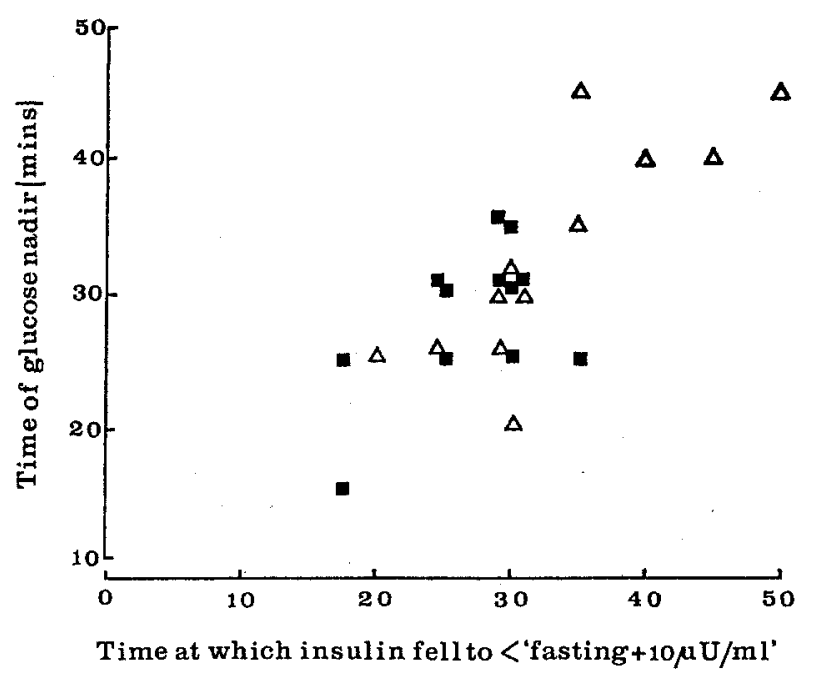

Fig. 2. Relationship between the time of glucose nadir and the time at which plasma insulin fell to $10 \mu \mathrm{U} / \mathrm{ml}$ above fasting insulin concentrations

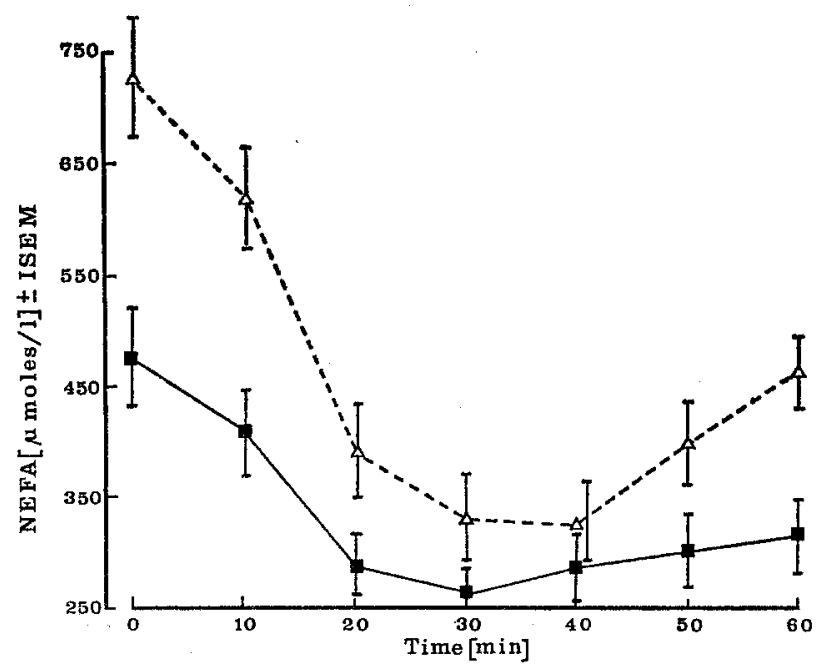

Fig. 3. Mean NEFA levels morning and afternoon ( $\mu \mathrm{Eq} / \mathrm{L}$ ) following intravenous insulin administration $(0.05 \mathrm{U} / \mathrm{kg}$ body weight)

sulin to drop to this level was $28.3 \pm 5.9 \mathrm{~min}$ in the morning, compared with the time to the glucose nadir of $29.3 \pm 6.2 \mathrm{~min}$. In the afternoon the times were $34.2 \pm 7.0 \mathrm{~min}$ for insulin and $32.0 \pm 7.9 \mathrm{~min}$ for glucose.

* This provided a more clear-cut endpoint then the fasting value itself. 


\section{Non-Esterified Fatty Acids}

NEFA levels before and after insulin administration are illustrated in Fig. 3.

Fasting NEFA values of $477 \pm 150 \mu \mathrm{Eq} / \mathrm{L}$ in the morning were significantly lower than those in the afternoon $(725 \pm 196 \mu \mathrm{Eql} / \mathrm{L})(p<0.001)$. Following insulin administration, NEFA levels fell significantly more slowly in the morning $(2.6 \pm 1.0$ per cent per min) than in the afternoon $(3.6 \pm 1.6$ per cent per minute) $(p<0.005)$, in contrast to the effect of insulin on blood glucose levels. Eventually a nadir was reached which, like the glucose nadir, correlated well with the time at which insulin levels reached $10 \mu \mathrm{U} / \mathrm{ml}$ above the fasting level $(\mathrm{r}=0.55 ; p<0.01)$ (Fig. 4). The mean NEFA nadir occurred $30.5 \pm 8.3 \mathrm{~min}$ after

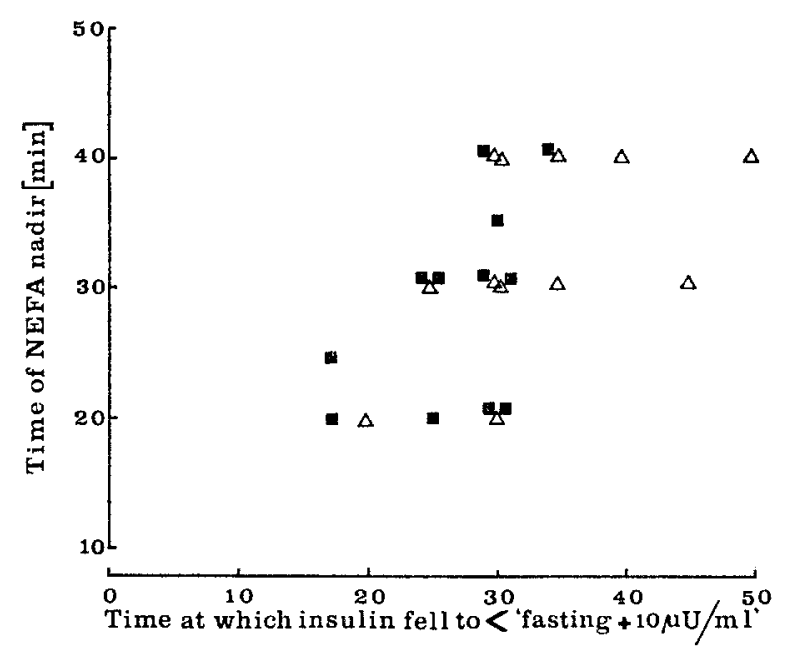

Fig. 4. Relationship between the time (mins) of NEFA nadir and the time at which plasma insulin fell to $10 \mu \mathrm{U} / \mathrm{ml}$ above fasting insulin concentrations

the insulin injection. Like the blood glucose, the total fall in NEFA values was significantly correlated with the fasting level, both in the morning and in the afternoon ( $\mathrm{r}=0.78 ; p<0.001)$ (Fig. 5). However, the percentage fall of NEFA in the morning $(46.7 \pm 14.5$ per cent) was significantly less than the percentage fall in the afternoon $(60.3 \pm 13.9$ per cent $)(p<0.001)$. There was a significant inverse correlation between the percentage fall in NEFA and the percentage fall in glucose $(\mathrm{r}=0.54 ; p<0.01)$ when the data for both morning and afternoon were combined (Fig. 6).

If one considers the caloric values of glucose and fat respectively, then the diminution of glucose fall in the afternoon is compensated by the increased fall of fatty acids. The calculated fall in the calorific value of plasma produced by $0.05 \mathrm{U}$ insulin $/ \mathrm{Kg}$ comes to
$2.2 \pm 0.5 \mathrm{cals} / 1$ in the morning and $2.3 \pm 0.5 \mathrm{cals} / 1$ in the afternoon. Also there is a significant correlation $(\mathrm{r}=0.70 ; p<0.01)$ between the fall in calories in the morning and afternoon (Fig. 7).

\section{Plasma Growth Hormone}

Fasting plasma growth hormone levels were low and not significantly different $-1.3 \pm 2.6 \mu \mathrm{IU} / \mathrm{ml}$ in the morning and $1.5 \pm 1.3 \mu \mathrm{IU} / \mathrm{ml}$ in the afternoon. These levels are well within the normal range for unstressed adult males. The growth hormone response to hypoglycaemia began at $50 \mathrm{~min}$ after insulin injection in both sets of studies (Fig. 8). The rise in growth hormone was greater in the afternoon than in the morning and the difference became significant $(p<$ 0.05 ) at each time interval from $60 \mathrm{~min}$ after the start of the test.

\section{Discussion}

In a previous study [17] it was shown that intravenously injected insulin $(0.1 \mathrm{U} / \mathrm{Kg})$ had a maximal effect on the rate of fall of glucose within $5 \mathrm{~min}$ of its injection and that glucose levels fell continuously to reach a nadir, which approximated to the time that plasma insulin reached near-fasting levels. In the diabetic subjects investigated, blood glucose levels fell more slowly than in the controls, but insulin also left the plasma at a slower rate. Consequently, the fall in glucose levels continued for a longer period (44 min in the diabetics compared with $27 \mathrm{~min}$ in the controls). Thus, by the time the nadir was reached, virtually the same proportion (67\%) of glucose had disappeared in the diabetic as in the control group (70\%). In the present study, glucose levels fell more slowly in the afternoon than in the morning, but, in contrast to the diabetics of the previous study, there was no appreciable difference in insulin disappearance at the different times of the day and no significant difference in the times of the glucose nadir. Therefore, the proportion of glucose which disappeared in the afternoon (32\%) was significantly less than the proportion leaving the blood in the morning (48\%). It follows that the mechanism producing insensitivity to insulin in the afternoon is different from that in diabetes.

It has previously been reported $[1,20]$ that fasting levels of NEFA are higher in the afternoon than in the morning. Our present studies confirm these findings. In several respects the effect of insulin on NEFA was similar to its effect on glucose. A maximal effect was observed soon after insulin administration, NEFA levels fell to a nadir which coincided with the time at 

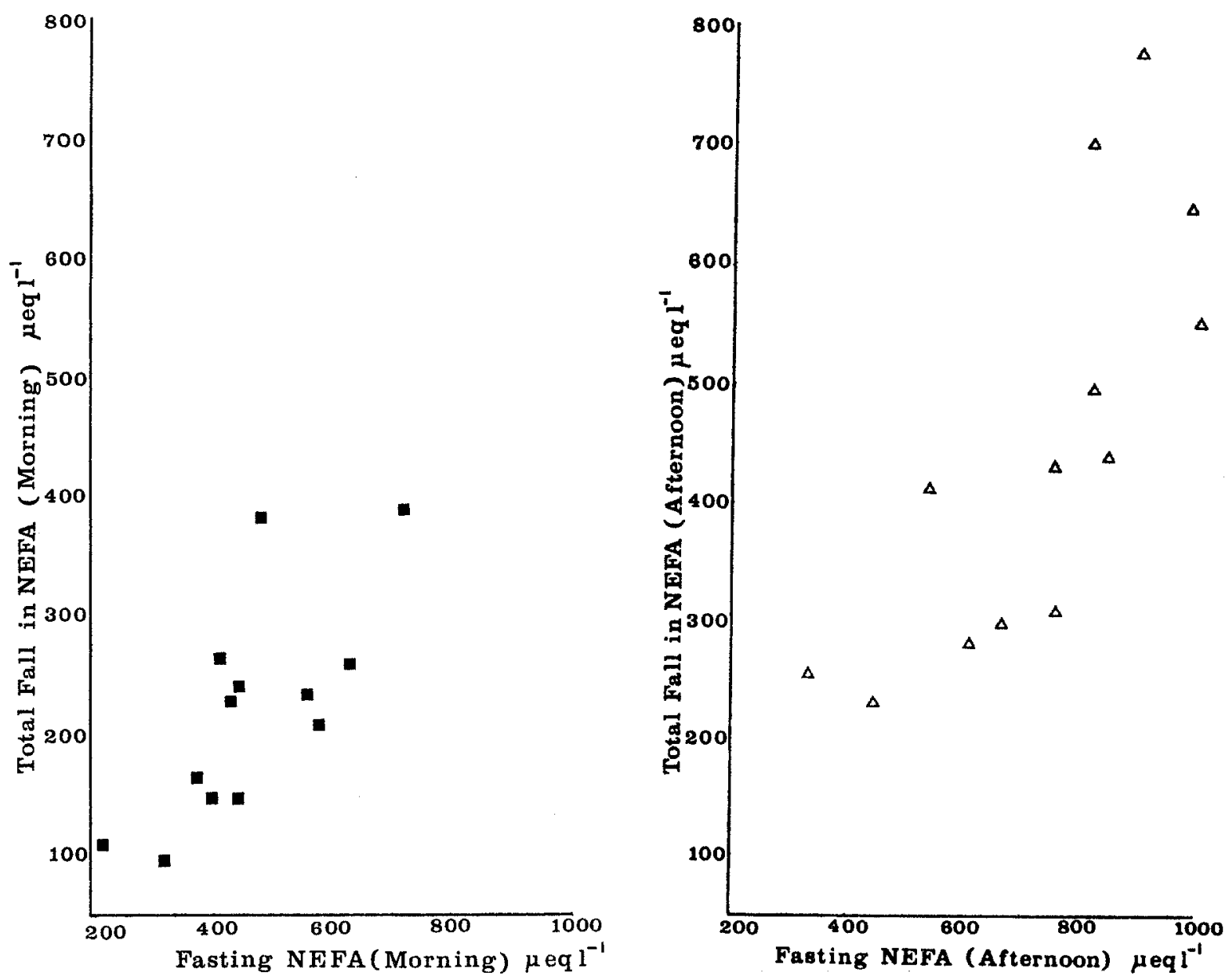

Fig. 5. Relationship between fasting NEFA $(\mu \mathrm{Eq} / \mathrm{L})$ and fall in NEFA concentration following insulin injection

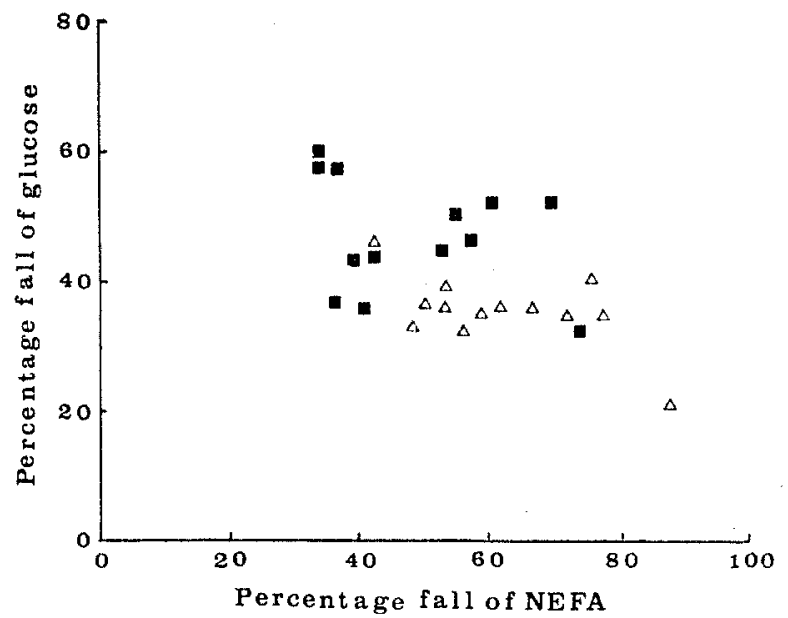

Fig. 6. Relationship between percentage fall of glucose and percentage fall of NEFA following insulin administration

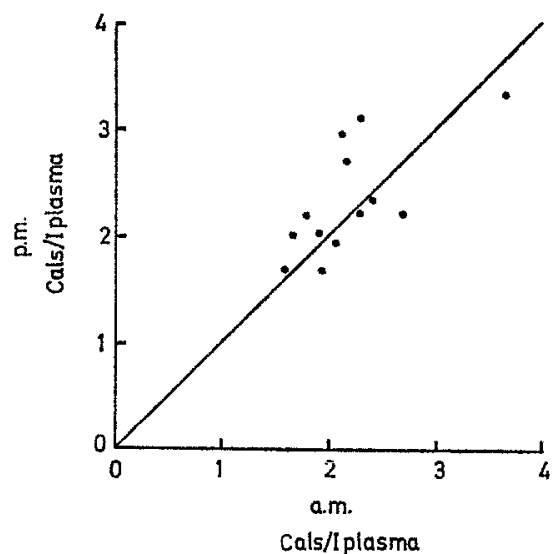

Fig. 7. Caloric output calculated from changes in NEFA and glucose concentrations. Relationship between morning and afternoon in calories per litre of plasma 
which insulin levels had fallen to $10 \mu$ units above the fasting level, and the total proportional fall of NEFA was related to the initial fasting level. There was diminished sensitivity of glucose to insulin in the afternon; however, NEFA levels fell faster and the proportional fall of NEFA was greater in the afternoon.

There are several independent mechanisms by which insulin reduces blood glucose values, including the facilitation of glucose transport across cell membranes [10] and the inhibition of glucose release from the liver [9]. We are not aware of any direct evidence that insulin may also stimulate the transport of fatty acids into the cells, although the possibility is suggested by the observations of Marini et al. (12), who showed that insulin administration to the isolated, newborn lamb's heart resulted in nett uptake of NEFA by the myocardium. It is well established that

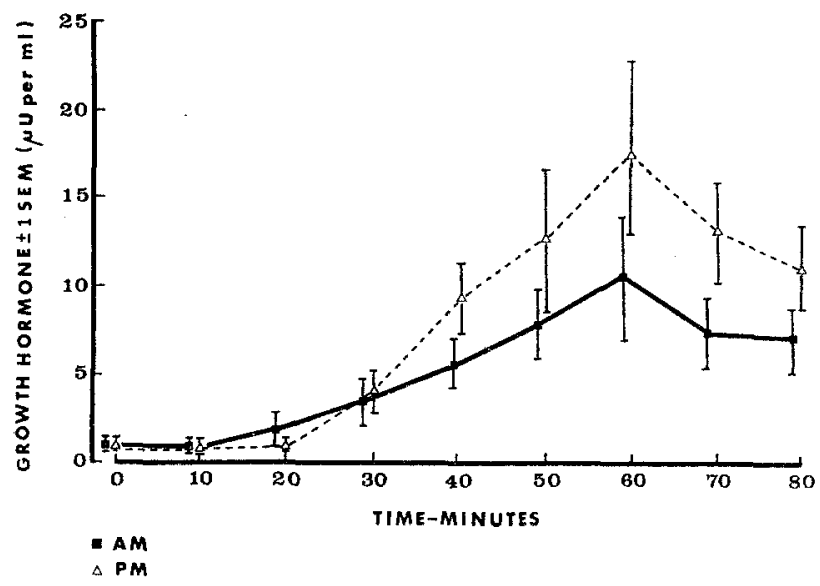

Fig. 8. Growth hormone $(\mu \mathrm{IU} / \mathrm{ml})$ response to insulin induced hypoglycaemia

insulin inhibits lipolysis [11] and at least part, if not all, of the fall of NEFA which occurs following insulin administration is due to the normal course of NEFA metabolism in the absence of further fatty acid release into the circulation. It is possible that insulin is more inhibitory to lipolysis in the afternoon than in the morning, but it is also possible that the more rapid disappearance of NEFA in the afternoon is due to an increase in NEFA utilisation, perhaps re-esterification [4]. This possibility is supported by the studies of Carroll and Nestel [1] and of Zimmet et al. [20], who showed a much steeper fall of NEFA following a glucose load in the afternoon or evening than in the morning, even though the insulin response to the glucose was significantly lower post-meridian.

Hales and Randle [5] observed that subjects on a low carbohydrate diet developed high fasting NEFA levels and impaired oral glucose tolerance. Randle $e t$ al. [14] postulated an interaction between glucose and fatty acid metabolism via a giucose-fatty acid cycle in which metabolism of glucose to glycerol phosphate leads to the synthesis of triglyceride by combination with fatty acids; in muscle, increased fatty acid metabolism inhibited the metabolism of glucose. These authors suggested that such a control system had important advantages for organisms that fed only intermittently, because it resulted in a switch from carbohydrate to fat as the main energy provider at times of carbohydrate deficiency. This would also allow for the maintenance of glycaemia, essential for cerebral metabolism, during periods of starvation. The concept that increased fatty acid metabolism by muscle tissue leads to impaired glucose metabolism by that tissue and possibly to impaired glucose tolerance of the whole organism has received support from experiments in man and laboratory animals $[16,18]$. In the present study, diminished insulin sensitivity (glucose disappearance) was related to increased NEFA disappearance (Fig. 6) as well as to higher fasting NEFA levels. The higher fasting NEFA level in the afternoon, with a circulating insulin level similar to that in the morning, implies a lesser antilipolytic effect of insulin and also a higher rate of NEFA disappearance to match the higher rate of production. The effect of the injected insulin may therefore be primarily antilipolytic, though we cannot rule out a direct effect upon NEFA catabolism or transport. Increased metabolism of NEFA in the afternoon may thus explain our finding of "insulin resistance" in terms of Randle and co-workers' hypothesis.

It is interesting that the same dose of insulin should produce the same fall in the caloric value of the plasma and also, presumably, extracellular fluid, in the morning and in the afternoon, even though there was a considerable difference in the proportions of glucose and fatty acids. Both in the morning and afternoon tests the patients were at rest; on average therefore the energy output on both occasions would be the same.

The cause of the raised NEFA levels and, possibly, increased NEFA metabolism remains unknown. The diurnal variation in cortisol secretion is not a likely explanation, because cortisol levels are higher in the morning than in the afternoon. The mean fasting growth hormone levels were very low during both tests. In spite of a lesser degree of hypoglycaemia, the rise in growth hormone levels following insulin was greater in the afternoon than in the morning. Although this may indicate a diurnal variation in hypothalamic sensitivity to a fall in blood glucose, it could not account for the raised fasting NEFA levels; indeed it 
could not have had any effect until after the glucose (and NEFA) nadir.

Acknowledgements. We are grateful to our volunteers for their willing assistance. Mr. K. Kilbourn provided able technical assistance. Mr. L. Armitage prepared the illustrations. We thank the Department of Health and Social Security for financial support.

\section{References}

1. Carroll, K. D., Nestel, P. J.: Diurnal variation in glucose tolerance and in insulin secretion in man. Diabetes 22, 333-348 (1973)

2. Carruthers, M., Young, D. A. B.: Free fatty acid estimation by a semi-automated fluorimetric method. Clin. Chim. Acta. 49, 341-348 (1973)

3. Gibson, T., Jarrett, R. J.: Diurnal variation, in insulin sensitivity. Lancet 1972 II, 947-948

4. Gilbert, C. H., Kaye, J., Galton, D. J.: The effect of a glucose load on plasma fatty acids and lipolysis in adipose tissue of obese diabetic and non-diabetic patient. Diabetologia 10, 135-138 (1974)

5. Hales, C. N., Randle, P. J.: Effects of low-carbohydrate diet and diabetes mellitus on plasma concentrations of glucose, non-esterified fatty acids and insulin during oral glucose tolerance tests. Lancet 1963 I, 790-794

6. Hartog, M., Gaafar, M. A., Meisser, B., Fraser, R.: Immunoassay of serum growth hormone in acromegalic patients. Brit. med. J. 1964 II, 1229-1232

7. Jarrett, R. J., Keen, H.: Diurnal variation of glucose tolerance: a possible pointer to the evolution of diabetes mellitus. Brit. med. J. 1969 II, 341-344

8. Jarrett, R. J., Baker, I. A., Keen, H., Oakley, N. W.: Diurnal variation in oral glucose tolerance: blood sugar and plasma insulin levels, morning, afternoon and evening. Brit. med. J. 1972 I, 199-201.

9. Kalant, N., Csorba, T. R., Heller, N., The effect of insulin on glucose production and utilisation in diabetes. Metabolism 12, 1100-1111 (1963)

10. Levine, R., Goldstein, M. S.: Mechanism of action of insulin. Recent progress in hormone research 10, 343-380 (1955)

11. Mahler, R., Tarrant, M. E., Stafford, W. S., Ashmore, J.: Antilipolytic effects of insulin. Diabetes 12, 359 (1963)
12. Marini, A., Vercellio, G. B., Gabrielli, L. Sr., Agus, G. B.: Myocardial metabolism in the newborn lamb. Abstracts of European Society for Paediatric Research 83 (1973)

13. Morgan, C. R., Lazarow, A.: Immunoassay of insulin: two antibody system. Plasma insulin levels of normal, subdiabetic and diabetic rats. Diabetes 12, 115-126 (1963)

14. Randle, P. J., Garland, P. B., Hales, C. N., Newsholme, E. A.: The glucose fatty acid cycle. Its role in insulin sensitivity and the metabolic disturbances of diabetes mellitus. Lancet 1963 I, 785-789

15. Schalch, D. S., Kipnis, D. M.: Abnormalities in carbohydrate tolerance associated with elevated plasma nonesterified fatty acids. J. clin. Invest. 44, 2010-2020 (1965)

16. Seyffert, W. A., Madison, L.: Physiological effects of metabolic fuels in carbohydrate metabolism. 1. Acute effect of elevation of plasma free fatty acids on hepatic glucose output, peripheral glucose utilisation, serum insulin and plasma glucagon levels. Diabetes 16, 765-776 (1967)

17. Stimmler, L., Mashiter, K., Snodgrass, G. J., Boucher, B., Abrams, M. E., Insulin disappearance after intravenous injection and its effect on blood glucose in diabetic and non-diabetic children and adults. Clin. Sci. 42, 337-344 (1972)

18. Wahlqvist, M. L., Kaijser, L., Lassers, B. W., Löw, H., Carlson, L. A., The role of fatty acids and of hormones in the myocardial carbohydrate metabolism in healthy fasting man. Europ. J. Clin. Invest. 3, 57-65 (1973)

19. Whichelow, M. J., Grainger, S. L., Jarrett, R. J., Keen, H., Sturge, R. A., Stimmler, L.: Diurnal variation in response to intravenous glucose. Brit. med. J. 1974 I, 488-491

20. Zimmet, P. Z., Wall, J. R., Jarrett, R. J., Rome, R., Stimmler, L.: Diurnal variation in glucose tolerance: associated changes in plasma insulin, growth hormone, and non-esterified fatty acids. Brit. med. J. 1974 I, 485488

\author{
Dr. R. J. Jarrett \\ Dept. of Medicine \\ Guy's Hospital Medical School \\ London Bridge SE 19 RT \\ England
}

